\title{
Expectations for Help Within and Across the Formal Boundaries of Executives' Professional Advice Networks
}

\author{
Miller, Stewart R.; Mors, Marie Louise; McDonald, Michael
}

\author{
Document Version \\ Accepted author manuscript \\ Published in: \\ Management International Review
}

DOI:

$10.1007 / \mathrm{s} 11575-019-00390-x$

Publication date:

2019

License

Unspecified

Citation for published version (APA):

Miller, S. R., Mors, M. L., \& McDonald, M. (2019). Expectations for Help Within and Across the Formal Boundaries of Executives' Professional Advice Networks. Management International Review, 59(4), 617-642. https://doi.org/10.1007/s11575-019-00390-x

Link to publication in CBS Research Portal

\section{General rights}

Copyright and moral rights for the publications made accessible in the public portal are retained by the authors and/or other copyright owners and it is a condition of accessing publications that users recognise and abide by the legal requirements associated with these rights.

\section{Take down policy}

If you believe that this document breaches copyright please contact us (research.lib@cbs.dk) providing details, and we will remove access to the work immediately and investigate your claim. 


\section{Expectations for Help Within and Across the Formal Boundaries of Executives' Professional Advice Networks} Stewart R. Miller, Marie Louise Mors, and Michael McDonald

Journal article (Accepted version*)

\section{Please cite this article as:}

Miller, S. R., Mors, M. L., \& McDonald, M. (2019). Expectations for Help Within and Across the Formal Boundaries of Executives' Professional Advice Networks. Management International Review, 594), 617-642. https://doi.org/10.1007/s11575-019-00390-x

This is a post-peer-review, pre-copyedit version of an article published in Management International Review. The final authenticated version is available online at:

DOl: https://doi.org/10.1007/s11575-019-00390-x

* This version of the article has been accepted for publication and undergone full peer review but has not been through the copyediting, typesetting, pagination and proofreading process, which may lead to differences between this version and the publisher's final version AKA Version of Record. 


\section{EXPECTATIONS FOR HELP WITHIN AND ACROSS THE FORMAL BOUNDARIES OF EXECUTIVES’ PROFESSIONAL ADVICE NETWORKS}

STEWART R. MILLER

One UTSA Circle

University of Texas - San Antonio

San Antonio, TX 78249 USA

Phone: 210-458-6868

Email: stewart.miller@utsa.edu

\section{MARIE LOUISE MORS}

Kilevej 14A

Copenhagen Business School

DK-2000 Frederiksberg

Denmark

Phone: +45 38154262

Email:1m.si@cbs.dk

\section{MICHAEL MCDONALD}

One UTSA Circle

University of Texas - San Antonio

San Antonio, TX 78249 USA

Phone: 210-458-4586

Email: michael.mcdonald@utsa.edu 


\title{
EXPECTATIONS FOR HELP WITHIN AND ACROSS THE FORMAL BOUNDARIES OF EXECUTIVES' PROFESSIONAL ADVICE NETWORKS
}

\begin{abstract}
We develop a theoretical framework for executives' expectations for receiving help from professional contacts in their advice networks across national (local/nonlocal) and organizational (inside/outside) boundaries. Moreover, we examine the effects of relational duration and trust in the relationships. In a study using unique data on 1,807 professional relationships in a US-headquartered multinational consulting firm, we find that executives expect less help from outside contacts. This result is partially mediated by trust. Also, relational duration mitigates expectations for help from outsiders. Surprisingly, we find no evidence that executives expect less help from nonlocal contacts. Yet a test of nonlocal professional contacts reveals that geographic distance rather than cultural distance, affects the expectations for help. Another supplemental analysis shows that the type of help provided in the network influences the effects of organizational and national boundaries.
\end{abstract}

Key words Executive advice networks; expectations for help; service multinational enterprise; formal boundaries; professional contacts 


\section{Introduction}

Managers' abilities to obtain help from other professionals is an important determinant of their ability to succeed as leaders of their respective organizations. Scholars who focus on the upper echelons in organizations have recently turned their attention to the provision and receipt of help among senior executives. Prior studies in this area have shown that executives' abilities to access help from professional contacts in their advice networks (e.g., advice regarding strategic issues) impacts executive effectiveness (McPherson, Smith-Lovin and Cook 2001; Perry-Smith 2006; Sykes, Venkatesh and Johnson 2014; Zou and Ingram, 2013), innovation (Alexiev, Jansen, Van den Bosch and Volberda 2010; Kijkuit and van den Ende 2010), competitiveness (Wu 2008), and even firm-level performance (Geletkanycz and Hambrick 1997; McDonald, Khanna and Westphal 2008).

Given the important consequences of executives' expectations for task-related help, it becomes important to understand the significant drivers of executives' expectations for help from professional contacts in their respective networks. In this paper, we will define these contacts as the individual actors that executives rely on to do their job, both internal and external to the firm. While this issue has received some attention in prior work (Farh et al. 2010; McDonald and Westphal 2010; Nebus 2006), there is a general need for more research in order to enhance our understanding of the factors that influence executives' expectations for help from their professional contacts, and in particular, the impediments to expectations for help. Some prior research on the provision and receipt of advice in multinational settings has emphasized geographic distance and social identity-related factors as potential barriers to information and advice sharing (Farh et al. 2010; Nebus 2006). Related work on knowledge sharing in organizations has examined the effect of physical proximity and (dis)similarity of individuals (Haas and Cummings 2015; Tallman and Phene 2007). This body of work suggests that national boundaries might prevent executives from helping each other. However, other work by Gupta and Govindarajan (2002) and Murtha and associates (1998) indicates that national boundaries may not be an impediment to expectations for help among executives who possess a so-called "global mindset". These disparate views on the potential implications of national boundaries further reinforce the need for research in this area.

Organizational boundaries may also impede expectations for help amongst executives. For example, some scholars have argued that help might be more readily available from professional contacts within the organization (Brass, Galaskiewicz, Greve and Tsai 2004; Katz and Allen 1982). Yet, others contend that colleagues inside the organization are perceived as a greater competitive threat than outsiders (Menon and Pfeffer 2003; Menon, Thompson 
and Choi 2006). As a result, people expect to receive less help from professional contacts within the organization than from external contacts. Prior work that has examined efforts to obtain advice from external contacts in an executive's network (Geletkanycz and Hambrick 1997; McDonald and Westphal 2003) has not systematically examined the expectations for help from contacts outside versus inside the organization (e.g., Farh et al. 2010). Inter-organizational knowledge sharing among lower-level employees has been shown to be difficult (Darr, Argote and Epple 1995). Nevertheless, executives have accumulated skills and experience and wrestle with complex issues that likely affect expectations for help in different ways than lower-level employees. For example, the demands of the executive suite require a sense of who is able to provide value-added advice that is in the best interests of the focal executive. Hence, research findings regarding entry-level employees or middle managers of the organization may not be readily transferable to the issue of senior executives' expectations for help from professional contacts in their advice networks.

The characteristics of the relationships between executives and their contacts may also affect executives' expectations for help with their work. This is important because relational characteristics may influence expectations for help within and across geographic and organizational barriers. For example, prior research suggests that relational duration plays an important role in the willingness of individuals to share information (Inkpen and Tsang 2005). Yet, this variable remains under-researched in work on executives' expectations for help. Moreover, prior research has underscored the role of trust in individuals' relationships (Levin, Whitener and Cross 2006; Nebus 2006), including the mediating role of trust in relationships that span organizational and national boundaries (Evans 2015; Levin and Cross 2004). Yet, we do not know if trust might affect senior executive relationships differently. It has also been suggested that relational duration influences the trust between knowledge sources (Coulter and Coulter 2002; Levin et al. 2006), which calls into question how this variable affects executives' expectations for help.

We seek to address the outstanding theoretical and empirical issues outlined above and hence consider the following research questions: First, how do national and organizational boundaries affect executive's expectations for help from professional contacts in their advice networks and, second, does relational duration influence these associations? These questions are practically important, in part, simply because many executives rely on professional contacts who reside in other countries or who work for other organizations (Hansen and Løvås 2004; Mors 2010). Moreover, the available evidence suggests that, because executives from other nations or organizations are more likely to provide non-redundant information and alternative perspectives on task-related issues (e.g., Burt 1992; McDonald 
and Westphal 2003), accessing their views can be especially beneficial to a focal executive (Beckman and Haunschild 2002; Zou and Ingram 2013).

We test the predictions derived from our theoretical model using a unique primary dataset that includes survey responses from senior executives in a US-headquartered multinational professional services firm regarding their expectations for help from their professional contacts. Access to help has been shown to be especially important for performance in professional services firms (Evans 2015; Faulconbridge and Muzio 2016). Contrary to some existing theory, our findings suggest that, in general, national boundaries do not affect executives' expectations for help from professional contacts in their advice networks. In general, our results support the prediction that organizational boundaries negatively affect expectations for help. However, in supplemental analysis, we examine expectations for help based on the type of help to be provided - i.e., expectations for help from career sponsors, as well as help with knowledge development and knowledge sharing. These supplemental results indicate that executives' expectations for knowledge development and knowledge sharing help is affected only by organizational boundaries, where outsiders are expected to be less helpful. This result also holds for career sponsors, but for career sponsor contacts we also find that the partners expect their nonlocal contacts to be helpful. This is likely because these are contacts that are committed to supporting them in their careers, regardless of geographic boundaries. Finally, we show that relational duration mitigates the effects of outsider status on perceived expectations for help from a contact.

Our study makes a number of contributions to the nascent literature on senior executives' expectations for help from professional contacts in their advice networks. A core contribution of this paper is that it is one of the few studies to systematically consider the effects of national boundaries (local versus nonlocal professional contacts) and organizational boundaries (insider versus outsider professional contacts) on executives' expectations for help. These findings are especially noteworthy given that Alexiev and associates (2010) found that professional contacts both inside and outside organizations help with innovations. Although we find geographic boundaries do not influence expectations for help, in general, a supplemental analysis consisting of only nonlocal professional contacts reveals that geographic distance -- rather than culture distance -- adversely affects expectations for help, which sheds new light on the role of distance in the liability of foreignness (Zaheer 1995). In another supplemental analysis, our results suggest that executives' expectations for help may be influenced by the type of help from outsiders and nonlocals. Further, we contribute to the understanding of executives in professional services firms by considering how the type of help influences the roles played by organizational and national boundaries in determining executives' expectations 
for help. Considering the different types of help allows us to reveal nuances in the relationships. In particular, we are able to show that there are boundary conditions for an executive's expectation for knowledge sharing help, which extends recent work by $\mathrm{Wu}$ (2008). Finally, we build on and extend recent work that has considered how relational characteristics influence the effects of national and organizational boundaries on expectations for help by executives (Wu 2008). In particular, we show that relational duration moderates the effects, whereas trust mediates the relationship.

\section{Theory Development}

Our theoretical framework examines a focal executive's expectations for help from professional contacts in their advice networks. As we take the executive's perspective, we refer to the advice seeking literature, which has examined focal actors' proximity and (dis)similarity to their professional contacts (e.g., Farh et al. 2010; Haas and Cummings 2015; Hansen 2002; Nebus 2006). Similarly, prior work on CEO's advice networks has focused on executives at other firms (McDonald and Westphal 2003; 2010). Hence, we consider national boundaries (whether or not the focal executive and the professional contact reside within the same country) and organizational boundaries (whether or not the focal executive and professional contact work for the same organization; Alexiev et al. 2010). As we consider the relationships that executives have to professional contacts it is also relevant to consider the characteristics of the relationships themselves. Recent work has shown that trust and duration of the relationship are important factors that affect both the interactions themselves, as well as, the performance of the relationships (Berkovitz and Feldman 2011; Vanneste, Puranam and Kretschmer 2014). Hence, we also consider how trust and relational duration affect the expectations for help from professional contacts. In particular, we examine how relational duration moderates the effects of national and organizational boundaries on the expectations for help from professional contacts. And, finally, we argue that trust mediates the effects of national and organizational boundaries on the expectations that executives have for receiving help from their professional contacts. Our theoretical framework is shown in figure 1.

\section{INSERT FIGURE 1 ABOUT HERE}

\subsection{National boundaries and expectations for help}

Scholars who study professional relationships between organizational members have given some consideration to the possible implications of national boundaries. Lack of physical proximity between an individual and a given professional contact is an obvious problem (Farh et al. 2010; Hansen and Løvås 2004; Nebus 2006). 
Hence, the role of geographic proximity has been shown to affect outcomes like knowledge sharing and innovation (e.g., Hansen and Løvås 2004). An oft-employed line of argument is that lack of proximity between professional contacts makes it more difficult to interact in order to resolve problems (Cramton 2001). Similarly, national differences make it increasing difficult to communicate effectively because of fewer opportunities to partake in face-to-face exchanges and establish a "shared task-related cognitive schema" that can be used to reconcile communication gaps due to differences in national origin (Haas and Cummings 2015, p. 40). While crossing national boundaries offers access to more diverse knowledge, it may also increase the difficulties associated with gathering and integrating information and knowledge (e.g., Mors 2010). Zipf (1949) similarly asserted that relationships between less proximate individuals require more effort to maintain than relationships between proximate contacts.

Given that a focal executive will tend to see greater difficulties in acquiring information from contacts situated in different countries, it seems reasonable to expect that their contacts will face analogous costs in sharing knowledge with the focal executive if they are situated in different countries. Crossing national boundaries may also exacerbate problems with diffusion of responsibility (Campbell, Eden and Miller 2012), whereby nonlocal contacts feel especially weak obligations to provide help when help is available from multiple contacts. Consequently, we expect that a focal executive will have lower expectations for help from nonlocal contacts than from local contacts (i.e., those situated in the same country as the focal executive). Hence,

Hypothesis 1: Executives will have lower expectations for help from nonlocal contacts than from local contacts in their professional networks.

\subsection{Organizational Boundaries and Expectations for Help}

An organization brings together individuals, who otherwise, might not communicate. The formal organization assigns job roles that mandate and facilitate interaction between its members (Blau 1973; Ibarra 1992). As a consequence, organizational boundaries represent an important driver of organization members' professional relationships (Brass et al. 2004; Dahlander and McFarland 2013; Zou and Ingram 2013). Hence, actors that work for the same organization are more likely to establish a new relationship or reinforce an existing relationship as organization members are most likely to interact within the boundaries of formal organization structures and units (Ibarra 1992).

Because formal organization boundaries mandate and facilitate interaction in organizations (Blau 1973), insiders are more likely to form relationships with other insiders and those relationships are more likely to persist (Dahlander and McFarland 2013; Ibarra 1992). Even though a larger number of relationships across organizations is 
generally associated with the acquisition of new strategic capabilities, relationships that span organizational boundaries require additional development costs, as contacts are likely to have divergent interests. Outsiders will therefore require more time to understand the nature of the executive's problem, synthesize information, and deliver a recommendation to the focal executive (Cramton 2001; Mors, Rogan and Lynch 2018). We therefore predict that executives will expect to receive less help from outsiders (i.e., professional contacts from other organizations) than from insiders (i.e., professional contacts from inside the focal executive's organization). In formal terms,

Hypothesis 2: Executives will have lower expectations for help from firm outsiders than from firm insiders in their professional networks.

\subsection{Mediating Role of Trust}

The arguments presented above suggest a number of mechanisms through which the non-local and firm outsider status of professional contacts might negatively impact expectations for help. In this section, we highlight an additional likely mediator of these relationships: a focal executive's lower levels of trust of non-local and outsider contacts.

Trust facilitates cooperative behavior, risk sharing and information sharing that, in turn, attenuates the need for monitoring (Bradach and Eccles 1989; Powell and Smith-Doerr 1994; Williams 2007). As Wicks and associates (1999) noted, trust enhances cooperation, reduces agency and transactional costs, and improves an actor's ability to manage complexity and handle change. The need for trust usually arises when parties have something that is at risk such as proprietary knowledge about an organization or individual (Wicks, Berman and Jones 1999). Hence, a focal individual must have sufficient assurance in another individual's motives and future actions to be willing to count on that individual in circumstances that involve some potential risk to the focal actor (Doney, Cannon and Mullen 1998; Vanneste et al. 2014). It has therefore been shown that relationships with a high degree of trust involve superior knowledge transfer (Mayer et al. 1995) and lead to a greater willingness to share knowledge (Levin and Cross 2004; Zand 1972).

We therefore expect that trust is likely an important precursor to executives' expectations of getting help from a particular contact. Yet extant theory and evidence would also suggest that trust is more difficult to develop across national and organizational boundaries. A main contributing factor here is the individual actors' perception that members of other groups - for example, members of other organizational or country groups - are less trustworthy compared to members of their own respective social groups (Levin et al. 2006; Tsui and O'Reilly 1989). Hence, national boundaries could lead to lower levels of trust between two actors (Doney, Cannon and Mullen 1998). For example, sociologists have established that social similarity (i.e., homophily) facilitates communication and builds 
trust (Lazarsfeld and Merton 1954). Thus, we expect that an executive will tend to view contacts located in other countries as comparatively less trustworthy than their local contacts. We therefore contend that building trust is more difficult when crossing national boundaries. When a focal executive experiences lower levels of trust of particular professional contacts, then that executive is likely to be less confident that those contacts have their best interest in mind. Therefore, it also seems likely that lower levels of trust will be associated with the expectation that task related help will be relatively less forthcoming from such professional contacts.

Developing trust between two actors can also be difficult across organizational boundaries because individuals who are "out-group" members are considered less trustworthy compared to "in-group" members (Williams 2007). Senior executives are likely to view professional contacts that work at other organizations as "out-group" members based on their organizational membership (Hogg and Terry 2000). Moreover, other organizations will often have values, goals, and communication characteristics that may jeopardize or appear incongruent with those of a focal executive's organization and may also interfere with the development of trust (Sitkin and Roth 1993; Williams 2001). As already discussed, when a focal executive sees particular contacts as less trustworthy he/she is likely to see help as less forthcoming from those contacts. Hence, we hypothesize:

Hypothesis 3a: The relationship between nonlocal contacts and a focal executive's expectations for help from those professional contacts is mediated by trust.

Hypothesis $3 b$ : The relationship between firm outsider contacts and a focal executive's expectations for help from those professional contacts is mediated by trust.

\subsection{Moderating Effect of Relational Duration}

Relational duration has been associated with the intensity and quality of a relationship (Lee and Campbell 1992). Interacting over time leads to feelings of obligation and dependence in the relationship (Moran 2005). Consequently, as relational duration increases, concerns over opportunistic behavior wane as trust between actors in the relationship increases (Vanneste et al. 2014). Hence, a focal actor is more likely to expect that a professional contact will act in their best interest the longer the relationship has lasted. McPherson and associates asserted that geographic space affects the "thickness" of a dyadic relationship (2001, p. 430), and therefore, communication effectiveness and knowledge exchange. Relational duration is commonly considered as a proxy for relationship strength or endurance, which is difficult to achieve with both nonlocal and outsider professional contacts. In their study of new product development teams, Hansen and Løvås (2004) showed that established informal relationships helped to overcome the difficulties associated with geographic distance. Thus, we expect relationship duration to mitigate the previously 
hypothesized tendency for executives to expect less help from their nonlocal and outsider contacts in their professional networks. In formal terms:

Hypothesis 4a: The negative relationship between nonlocal professional contacts and a focal executive's expectations for help from those contacts is weakened by relational duration.

Hypothesis 4b: The negative relationship between firm outsider professional contacts and a focal executive's expectations for help from those contacts is weakened by relational duration.

\section{Methods}

\subsection{Sample and Data Collection}

We test our hypotheses in the context of a large multinational management consultancy. The firm was head-quartered in the US, but operated as a truly global firm with large offices in Europe, Asia and Australasia. The firm operated broadly within management consulting and provided consulting services across different industries and within competencies ranging from strategy to large change and IT implementation programs. The local partnerships operated their own P\&L and employed professionals locally. Gaining access to the firm took almost two years of negotiations and as we were able to access the senior partners in the firm, we were constrained to studying a limited sample in detail. The data were collected using a standard ego-centric network survey (cf. Burt 1992) administered to a random sample of 102 senior partners. At the time of data collection in late 1999 and early 2000, the firm operated in more than 100 countries, had annual sales of more than US $\$ 500$ million, and employed more than 55,000 professionals worldwide ${ }^{1}$. The firm had a partnership structure where the senior partners we studied were at the upper echelon and responsible for not only developing and implementing business with clients, but also for managing the firm. Studying senior executives at the same hierarchical level within the firm allows us to examine the determinants and consequences of the availability of help from professional contacts without the confounding effects of organizationaland role- related factors. These senior partners perform roles similar to those performed by senior executives in firms operating in other industries. They are responsible for both developing new business and the implementation and operation of existing business activities. The partners all had management responsibility and were responsible for

\footnotetext{
${ }^{1}$ To preserve anonymity of the firm, we are unable to provide the exact level of income and size of the firm. For further descriptions of the firm and data collection process, please see Mors (2010). Note that the study by Mors (2010) differs in that it looks at innovation performance based on network structures across boundaries. Further that examines the partner aggregate-level data. In contrast, we are here concerned with expectations for help in a focal relationship and therefore examine the dyadic (relationship-level) data.
} 
managing anywhere from a few hundred to a thousand consultants. As such we believe our findings are generalizable to senior executives in other multinational settings.

Testing our hypotheses required data on the senior executives' expectations for help from their professional contacts, the attributes of these contacts, as well as data on the relationship itself. The data were collected via an egocentric network survey based on the design developed by Burt (1992) and administered during 90-minute face-to-face interviews. The exact questions were adapted to the specific empirical context in collaboration with senior management and our main sponsor at the CEO's office of the firm. A pilot test of the survey was conducted using the firm's internal mail service to send questionnaires to six partners in the US and UK. The pilot suggested that because of the complexity of the network component of the survey, the questionnaire was likely to be perceived as taking too much time and attention from the firm's most senior executives. This might have compromised the response rates and potentially lead to negative reactions of our research across the firm. Based on this feedback, we therefore decided to administer the survey in person. Five trained interviewers conducted these interviews and were therefore also available to answer clarifying questions. The respondents to the pilot survey were not part of the final data sample. Instead, 147 partners were chosen at random through a clustered sampling procedure from ten of the largest offices -Chicago, San Francisco, New York, London, Paris, Frankfurt am Main, Milan, Madrid, Sydney, and Tokyo. Consequently, the survey was filled out and the data collected in a face-to-face interview format during 90-minute meetings with one of the five trained interviewers. Due to the global nature of the firm and as the working language was English, all surveys were completed in English. The interviewers first introduced the study and the survey briefly and then asked the partners to make a list on a blank piece of paper of the 10 to 15 professional contacts that they considered to be most important for them to be successful in their work. We found that this procedure helped put the partners in the right mind-set to start thinking about their professional network and how they utilized the professional contacts in their work. We then asked them to fill in the network survey without feeling bound by the initial list of contacts. The interviewers were on hand to ensure the survey was filled out correctly and to answer any clarifying questions. In sum, for both the interviews and the survey procedures, we followed established standards for achieving rigor in research practice (see Chidlow, Ghauri, Yeniyurt, and Cavusgil 2015; Chidlow, Plakoyiannaki and Welsh 2014; Squires, 2009; Welch and Piekkari 2006). 
A total of 133 survey interviews were scheduled and of these, 102 survey interviews were finally completed, yielding a final response rate of $69 \%(102 / 147)^{2}$. The collected survey data yields a final sample of 1,845 dyadic relationships, with 1,807 usable observations due to missing data on different variables included in our analyses. The survey was divided into three main parts: (i) demographic data for each partner (ii) identification and description of each partner's contacts and (iii) characteristics of each of these contacts. The questions used to identify the partners' contacts were adapted to the specific empirical context. Thus, to generate the list of contacts, the partners were asked on whom they relied to identify new business opportunities, to negotiate and close deals, to provide new knowledge and expertise, to develop their skills, to provide operational support, and sponsor their projects. A partner could identify a maximum of 24 different contacts. The questions about the characteristics of the contacts were used to create our dependent and independent variables as explained in more detail below.

\subsection{Dependent Variable}

Expectations for help. To measure the dependent variable for our hypotheses, we used a question in the second part of the survey asking each of the 102 partners the following question: "How willing do you think each person listed would be to help you in a very difficult business circumstance? (circle best approximation)" The responses were indicated on a five-point Likert scale with (1) representing the answer "less willing" and (5) representing "more willing." Thus, higher values on this scale reflect a greater expectations of help to the focal partner by a given contact in the partner's network.

\subsection{Independent variables}

Nonlocal. We included a dummy variable measuring whether each of the partner's contacts was local or not. This variable equals one if the contact is not located in the same country as the focal partner and zero if the contact is located in the same country as the focal partner. ${ }^{3}$

\footnotetext{
${ }^{2}$ Some of the initial 133 interviews were cancelled due to illness or the partners being unexpectedly out of the office when the interviewers visited. To rule out systematic bias between the partners sampled and those that participated in the final interviews, we tested for differences in the mean values of the main organizational units of the firm (Levene 1960). There were no significant differences across industry group and functional specialization and only slight differences in geographic location. These differences were due to the availability of the interviewers in different geographic locations at different times and not the partners' propensity to participate.

${ }^{3} \mathrm{We}$ considered a cultural distance measure in supplemental analysis. In that case, every local contact, i.e., contacts located in the same country as the focal partner, was assigned a culture distance of zero. The coefficient for cultural distance was not significant, which is consistent with the general findings on nonlocal as reported.
} 
Outsider. We included a dummy variable measuring if a contact was an insider or outsider to the firm. This variable equals one if the contact is an outsider (not a member of the focal firm) and zero if the contact is a member of the firm.

\subsection{Moderator variable}

Relational duration. This variable reflects how long the focal managing partner has known a particular contact and is reported in number of years. In the regression analyses, we use the natural log of this variable due to its skewed distribution (Kennedy, 1998).

\subsection{Mediating variable}

Trust. To measure this variable, we used a 5-point Likert scale based on the response to the following question: "To what degree do you trust that each person listed has your best interest in mind"? A higher value corresponds to the focal partner having a higher degree of trust in a particular contact.

\subsection{Control variables}

A number of controls related to the focal partners are included in the analyses. We also include a number of controls related to the dyadic relationships.

Country. We include dummy variables for the country that each partner is located in, as there might be differences across the eight countries in our data in how willing the partners perceive that their professional contacts are to help them.

Expatriate. Similarly, there might be differences in whether partners perceive their contacts to be more or less willing to help if they are expatriates. This dummy variable equals one if the focal partner is located in a different country office than where they are originally from, and zero otherwise.

Relationship strength. Previous studies of network characteristics have shown that the strength of the tie is likely to affect advice seeking or knowledge sharing (e.g., Hansen 1999; Hansen et al. 2005). We therefore also control for the strength of each of the relationships in the partners' networks. While frequency is a commonly used measure of relationship strength (Granovetter 1973), closeness may be a more accurate measure as two people may interact frequently, but still not be particularly close (Marsden and Campbell 1984). This variable was measured on a 5-point Likert scale where (1) equals 'distant' and (5) equals 'especially close' and was based on the question: "How close are you with each person?" 
Junior position. It could be that the outcome variable is affected by whether the contact is junior or equal in rank to the partner. For example, it may be that partners are more likely to expect those of equal rank to be more willing to help them. We therefore include two dummy variables controlling for the rank of each of the partners' contacts. This first dummy variable is junior position, which equals 1 if the contact has a rank that is lower than the focal partner, and zero otherwise.

Senior position. This dummy variable equals 1 if the contact has a rank that is equivalent in the hierarchy to the partner, and zero otherwise.

In subsequent analyses, we controlled for the type of help provided in the relationships. We therefore included three controls to account for the type of help. The first of these controls is knowledge sharing help. We received the information for this variable from the name generator items in the questionnaire. These items tell us something about the type of content shared in those ties from which the executives expect to receive help. We might expect that executives are more likely to expect contacts from which they receive valuable knowledge and expertise to be more helpful. Specifically, the item measures those contacts that the executives consider their "most important sources of valuable knowledge and expertise (e.g., industry, competency, functional)" coded as one if the contact falls into this category and zero otherwise.

Knowledge creation/development help. The second name generator item that we include is the answer to the question: "On whom do you rely to help you develop skills and knowledge in your area of expertise?" coded as one if the contact falls into this category and zero otherwise.

Sponsorship help. The final name generator item that we include indicates to what extent the executives rely on their contacts "to sponsor and support your projects and activities?" We include this item as we expect that the executives will be more likely to expect to receive help from contacts that also sponsor their activities.

It is important to note that respondents provided both information that led to objective measures (e.g., outsider, nonlocal and relational duration) and subjective measures (e.g., trust and perceived availability of help). Conway and Lance (2010) asserted that self-reports are clearly appropriate when the theoretical framework -- like the one in the present study -- involves perceptions of a focal actor (e.g., Judge, Bono and Locke 2000).

\subsection{Analyses}

To test our hypotheses, we use a multilevel model, which is common procedure when testing dyadic relationships contained in personal networks (Snijders, Spreen and Zwagstraa 1995). We ran a multilevel model using the xtmixed 
command in STATA 14. To test for mediation, we follow Baron and Kenny's approach (1986), taking into consideration that we are using multi-level modeling. For the mediation analysis, we use the ml_mediation command in STATA 14. Some of the survey items examined attributes of the focal partner, yet we focused on the dyadic relationships with each professional contact. Hence, the focal partner assessed specific items for each respective professional contact separately, reducing the likelihood of self-report bias. Nevertheless, we conduct a Harman single factor test to determine if self-reporting affects our results (Harman 1960). The single factor test indicated multiple factors with eigenvalues that exceeded one. The largest proportion of variance by a factor was 23.4 percent, which falls short of the 50 percent threshold. This result is not surprising since a focal partner must provide responses across their entire list of professional contacts.

\section{Results}

The summary statistics are reported in table 1. Table 2 presents the results of the focal executives' expectations for help from each of their professional contacts. Model 1 includes the control variables. These results indicate that the coefficients for relationship strength (as reflected by closeness of the relationship) and relational duration are positive and significant $(\mathrm{p}<0.000 ; \mathrm{p}<0.008)$. It seems unsurprising that partners are more likely to expect that contacts that they have known for longer and feel closer to are willing to help them. Similarly, we see that those contacts that they have higher trust in are also more likely to be perceived as willing to help $(\mathrm{p}<0.000)$. Moreover, the coefficient for junior position is positive and significant $(\mathrm{p}<0.011)$. Senior position is not significant. Perhaps the obligations entailed in the hierarchy means that the partners are more likely to expect that contacts junior to them are willing to help.

A test of difference in means of the dependent variable across countries suggested that the partners might differ in their perceived expectations for help $\left(\mathrm{Chi}^{2}=19.49, \mathrm{p}<0.007\right)$. The country control for Germany is negative and significant $(\mathrm{p}<0.044)$, suggesting that partners located in Germany are less likely than the partners in the US (the omitted dummy) to perceive their contacts to be willing to help. The control for the UK is positive and significant ( $\mathrm{p}<0.017)$, suggesting that partners in the UK are more likely than the partners in the US to perceive their contacts as willing to help. The other office controls are not significant, nor do excluding the office controls from our analyses change the results ${ }^{4}$. The coefficient for expatriate is not significant. Model 2 shows the results of the main

\footnotetext{
${ }^{4}$ In another supplemental analysis, we sought to examine whether there was a home-country bias with respect to expectations of advice from professional contacts. For this analysis, we split the sample and estimated the results for executives who were located in the same country as the corporate headquarters (i.e., the USA) separately and then for the executives who were located outside of the country of the corporate headquarters (all non-USA countries). In both
} 
hypothesized effects. In support of hypothesis 2 , the coefficient for outsider is negative and significant $(\mathrm{p}<0.000)$. In contrast, we do not find support for hypothesis 1, as the coefficient for nonlocal is not statistically significant ( $\mathrm{p}<0.564)$. The control for relational strength remains positive and significant in model $2(\mathrm{p}<0.000)$, but the control for duration loses significance $(\mathrm{p}<0.071)$. Duration is, however, highly correlated with trust and perhaps this conflates the result. Running the model without trust indeed reveals that relational duration remains highly significant $(\mathrm{p}<0.000)$ and the other variables are unchanged. Hence, we drop trust from the subsequent models as those models include interactions of other variables with duration.

\section{INSERT TABLES 1 AND 2 ABOUT HERE}

Model 3 includes the interactions with relational duration. The interaction with outsider is positive and significant $(\mathrm{p}<0.000)$, in support of Hypothesis $4 \mathrm{~b}$. However, the interaction with nonlocal is not statistically significant $(\mathrm{p}<0.945)$ and hence Hypothesis $4 \mathrm{a}$ is not supported. The coefficients for the main hypothesized variables remain essentially unchanged in terms of sign and significance in model 3. Although not hypothesized; for completeness, model 4 introduces an interaction term between outsider and nonlocal. This term is not significant. The coefficients on the main effects and interactions in model 4 are unchanged from those reported in model 3 . For the full model, the variance inflation factor test reveals a maximum individual value of 3.37 and an average value of 1.63. The VIF results are well below the generally accepted threshold of 10 , which suggest that multicollinearity is not a concern in our study.

Figure 2 provides a graphical representation of the interaction between outsider and relational duration. The figure plots the results from model 4 in Table 2. It shows clearly the partners are more likely to expect both firm insiders and outsiders to be willing to help the longer they have known them. Yet the effect is much stronger for outside contacts as can be seen from the slope of the graph. For inside contacts, relational duration has only a very small effect on the expectations for help.

INSERT FIGURE 2 ABOUT HERE

sets of analyses, the results were similar to results presented in tables 2 and 3 respectively. Hence, we conclude that there is not a home location bias in terms of expectations for help from professional contacts. 
We provide the mediation results testing hypothesis 3 in Table 3. In the first three models we test hypothesis 3a, i.e., the mediation effect of trust on nonlocal. In model 1 of table 3, we regress expectations for help on the controls and independent variables. The results in model 1 are comparable with those in model 3 in table 2. In model 2 of table 3, we regressed trust on the aforementioned controls and independent variables. Again, the interaction with nonlocal is not significant. Model 3 of table 3 is essentially the same as model 1, but with the addition of trust as an independent variable. The results reveal that there is no support for the direct, moderating hypotheses involving nonlocal, which violates the conditions for trust mediating the relationship between nonlocal and focal executives' expectations for help.

The final three models show mediation results of trust on outsider as hypothesized in hypothesis $3 \mathrm{~b}$. These results show that the coefficient for outsider is negative and significant $(\mathrm{p}<0.000)$. The coefficient for nonlocal $*$ relational duration is not significant. The coefficient for trust is positive and significant as expected ( $<<0.000)$. Moreover, the coefficient for outsider is negative and significant $(\mathrm{p}<0.000)$, while the coefficient for nonlocal is not statistically significant. We used the bootstrapping command in STATA version 14 to assess the significance of the indirect, direct and total effects, respectively. The results indicate that all three of these effects are statistically significant $(\mathrm{p}<0.000)$. In sum, we find in support of Hypothesis $3 \mathrm{~b}$ that the conditions for mediation were met for outsider. In particular, trust partially mediates the relationship between outsider and the focal executives' expectations for help.

\section{INSERT TABLE 3 ABOUT HERE}

\subsection{Supplemental Analyses}

The extent to which organizational and national boundaries influence expectations for help may depend on the type of help that a professional contact can offer to an executive. We examined expectations for help according to the type of help - knowledge creation/development help, knowledge sharing help, and sponsorship help. Prior research has suggested that the flows of resources in ties, knowledge flows in particular, may be affected by distance (Alavi and Leidner 2001), whereas relationships to sponsors may be less affected. The main results reported in Table 2 are consistent with this, as we see that the partners are more likely to expect those contacts they rely on to create knowledge and share knowledge to be helpful, whereas career sponsors are not expected to be more or less helpful. 
Expectations for knowledge creation/development help. Nonaka (1994) specified four interdependent and interconnected knowledge creation modes. Nonaka and Konno (1998) further showed that having a common location/place for knowledge creation is critical. The authors asserted that in-person interactions facilitate the diffusion of experiences, conversion of tacit knowledge to a codifiable form, and ongoing learning by individual actors (also see Alavi and Leidner 2001). Knowledge creation/development that draws upon in-person interactions tends to emphasize tacit knowledge, or what Haas and Hansen refer to as "personal advice usage" (2007: 1136). Nonaka and Konno (1998) alluded to a virtual location/place. We infer from Haas and Hansen that a virtual location/place entails codifiable forms of knowledge. Hence, we might expect knowledge creation/development help to be especially challenged by geographic and organizational boundaries. According to Glaeser and associates, "intellectual breakthroughs must cross hallways and streets more easily than oceans and continents" (1992, p. 1127).

As for knowledge sharing help, Kogut (1991) argued that knowledge gets diffused more quickly within national boundaries compared to across them. Although knowledge flows may be sticky across national boundaries, it eventually gets diffused (Tallman and Phene 2007). We infer, therefore, that executives' expectations of knowledge sharing help may be affected more by organizational boundaries than geographic boundaries. Lastly, help provided by sponsors may likely require the least in terms of effort and cognitive taxation. As such, sponsorship help may be impeded less by organization and geographic boundaries compared with knowledge intensive help (i.e., knowledge creation/development help and knowledge sharing help).

To determine if this was the case, we ran models with the types of help as dependent variables. The results for knowledge development help show that the coefficient for outsider $(\mathrm{p}<.000)$ was negative and significant. The coefficient for nonlocal was not significant. The results for knowledge sharing help were similar. Lastly, the results for sponsorship help indicated that the coefficient for nonlocal was positive and statistically significant $(\mathrm{p}<0.031)$, while the coefficient for outsider was negative and significant $(\mathrm{p}<0.000)$. We infer from the supplementary results that communication and logistical challenges are salient for more knowledge intensive help - specifically knowledge sharing and development help, which is consistent with prior work on multinational teams (Haas and Cummings 2015). In their study, Haas and Cummings also noted that "MNC team members in different geographic locations often lack awareness of, and appreciation for, the relevance of each other's knowledge" (2015, p. 40). Reflecting on Haas and Cummings (2015), our finding that national boundaries do not influence knowledge sharing help may suggest that more distant professional contacts may provide less relevant help. This prediction, however, needs to be 
validated in future research. Particularly as the least knowledge intensive of the three forms of help, namely sponsorship help, seems to be unaffected by national boundaries and not subject to communication and logistical impediments. Perhaps this result is because the career sponsors by definition are committed to helping the executives, regardless of any coordination obstacles generated by geographic boundaries.

In a test of robustness, we considered an alternative to multi-level modeling. For this robustness test, we used an ordered logit model (Kennedy 1998; Long 1997). However, given that the analysis is at the dyadic level, we cluster the standard errors based on the focal partner in order to control for the fact that the data are nested - that is, the relationships are not independent in that they belong to a particular partner. The results of this analysis are consistent with the main findings reported here.

Approximately thirty percent of the focal executives had only local contacts in their network. In a supplemental analysis, we analyzed the subsample that excluded those senior partners with only local professional contacts in their networks. Again, the results are consistent with those reported on the full sample of partners.

To better understand if the geographic and cultural distance of nonlocal professional contacts affects the partners' expectations for help, we examined the cultural distance as well as the distance in miles between the partners and their nonlocal contacts. Following Hansen and Løvås (2004: 809), we created two cultural distance measures both based on the cultural indices developed by Hofstede (1980). The first measure uses the Kogut and Singh (1988) distance equation and the second is the Euclidean distance in terms of culture between the managing partner's country and the professional contact's country (Barkema and Vermeulen 1997). For the total sample of non-local professional contacts (N=235) neither the Kogut and Singh (1988) cultural distance measure, nor the Euclidean cultural distance are significant. There is, however, evidence that the geographic distance in miles is positive and significantly related to the expectations for help ( $\mathrm{p}$ 0.037). This finding suggests that geographic distance, rather than cultural distance, is the principle driver of expectations for help from nonlocal professional contacts. This may indicate that in an organization like the one we studied, where there is a mindset of sharing knowledge across geography, cultural distance based on national culture does not affect the expectations for receiving help. Distance in terms of miles does, however, play a role. In our setting, perhaps the global mindset has allowed for an organizational culture of knowledge sharing in spite of the geographic distance. Future work would have to further explore the nuances in interactions between geographical and cultural distance and the expectations for receiving help from professional contacts.

\section{Discussion and Conclusion}


This study sought to advance our knowledge of factors that impact executives' expectations for help from the contacts in their professional networks. We focused on the possible implications of the existence of geographic and organizational boundaries between a focal executive and his or her professional contacts. Moreover, we sought to enrich our understanding of the implications that relational factors might have for the effects of geographic and organizational boundaries on expectations for receiving help. We specifically considered the roles of relational duration and trust in the relationship between a focal executive and a professional contact.

While much of our theoretical framework was supported by the data, contrary to our prediction, our general findings provided no evidence that national boundaries affect executives' expectations for help from their professional contacts. The executives in our study did not expect to receive less help from contacts working in other countries. This was true even for ties that were of relatively short duration.

The empirical results did support our hypothesis that organizational boundaries function as a barrier to obtaining help from professional contacts. Respondents indicated that they expected to receive less help from those contacts who worked for other organizations. Overall our findings indicate that organizational boundaries have a powerful negative effect on the expectations for help from professional contacts. Prior research has underscored that firm outsiders offer non-redundant information and alternative perspectives that can be especially beneficial to a focal executive (e.g., Rodan and Galunic 2004). Our results suggest that, unfortunately, there can be significant challenges to obtaining help from firm outsiders. Also in line with our theory, the results revealed that the relationship between firm outsiders and the expectations for help is mediated by trust. Finally, our findings suggest that the relationship between firm outsiders and the expectations for help is moderated by relational duration. In line with our expectations, this interaction is mediated by trust.

The results for expectations for help from firm insiders versus outsiders warrants additional discussion. Our findings may indicate a "cognitive bias" on the part of some executives, who expect help from insiders, yet both insiders' and outsiders' advice has been shown to influence outcomes such as innovation (Alexiev et al. 2010). Hence, executives may forego valuable opportunities to obtain outsiders' advice - and even non-local contacts' advice - if they have such a bias. Hence, our study has important managerial implications in that executives' expectations for help need to be taken into consideration when examining the outcomes of actual help received.

The non-findings for national boundaries are surprising. Prior studies of non-executives have theorized that national boundaries and cultural dissimilarity between team members leads to less effective knowledge sharing and 
lower expectations for advice sharing between professional contacts. In general, we found no support for this relationship in our study. One compelling explanation for these non-significant findings is that the executives we study may possess a "global mindset" (Ananthram and Nankervis 2014). Scholars suggest a global mindset exists to the extent that managers have a "global business orientation and are adaptable to the local environment and culture" (Story and Barbuto 2011, p. 380). Others describe it in terms of "openness to and awareness of diversity across cultures and markets with a propensity and ability to synthesize across this diversity" (Gupta and Govindarajan 2002, p. 117). It seems likely that corporate executives of a multinational enterprise will be especially prone to developing a global mindset, while such a mindset will be less likely to be fully developed in non-managers and middle managers since it is "a product of our histories and evolve through an iterative process" (2002, p. 116). Through experiences that encompass the entire journey to reaching the upper echelons of management in a multinational enterprise, these executives are able to develop norms, accumulate knowledge, and refine skills to make national differences less salient.

Our supplemental analysis provides further insight into the effects of national, as well as organizational, boundaries. Knowledge sharing and creation/development help -- which may be construed as the most knowledge intensive types of help -- seems to be particularly affected by organizational boundaries, but not by national boundaries. In contrast, receiving help from career sponsors is expected even when these contacts are situated in different geographies. Perhaps the expectations are so strong that they forgo any potential geographic barriers. Our finding that executives expect less help from outsiders contrasts with -- at least in a broad sense -- prior research by Menon and Pfeffer (2003) and Menon, Pfeffer and Choi (2006), which indicated that internal sources of information are considered more of a competitive threat than external sources of information.

\subsection{Contributions}

Our paper makes a number of contributions to the nascent literature on the help senior executives receive from their professional contacts. First, our study is one of few to systematically consider how geographic and organizational boundaries influence expectations for help from professional contacts. Hence we are able to show that there are nuances in the expectations of receiving help, depending on the types of formal boundaries that executives have to cross. In particular, we show that organizational boundaries strongly influence expectations for help from professional contacts, but surprisingly that national boundaries have no significant effect. A robustness test of only nonlocal professional contacts reveals that geographic distance - rather than cultural distance - adversely affects expectations 
for help. This result provides new insights for the role of distance in the liability of foreignness (Zaheer 1995). Further, we find that trust mediates the relationship between the outsider status of a contact and the expectations for help. We also advance the understanding of expectations for help in executive relationships by examining how relational duration might mitigate the negative effects of outsider status. Finally, our study provides further insight into the role that the type of help provided plays in influencing the effect of national and organizational boundaries on expectations for help through executive advice networks.

\subsection{Limitations and Future Research}

Our study is not without limitations. First, our sample consists of focal executives from one organization-a multinational professional service firm. These partners are at the senior level of the firm and actively engaged in the management of the firm and as such their roles are comparable to those of senior managers in subsidiaries of large multinationals. Hence, while there are limits to the generalizability, we do believe our findings are transferable to other settings. Nevertheless, future research may consider executive contact networks in different settings such as, manufacturing where the responsibilities of senior executives may be more focused on implementation as opposed to new business development.

Second, the organization is headquartered in North America. Future research may consider samples of firms headquartered in other countries - especially more collective societies or ones with a high degree of uncertainty avoidance - to better understand the formation of executive networks and expectations for help in professional networks as this may differ across cultures. Regardless, future studies would benefit from taking into account organizational and personality factors as these may shed additional light on executives' expectations for help.

Third, as noted in the methods section, survey respondents provided objective and subjective measures that may introduce biases. However, for studies in which the theoretical framework involves constructs that are subjective in nature (e.g. perceptions or affect), self-reports are considered acceptable (Conway and Lance 2010; Judge, Bono and Locke 2000). As noted above, future research may consider actual help received, which is a related, though different construct.

\subsection{Managerial Implications}

Our study has important implications not only for how individual executives think about developing and maintaining their professional advice networks, but also for how the top management team thinks about influencing and facilitating networks in organizations. We found that the geographical location of executives' professional contacts has no effect 
on the expectations for help from those contacts, while the firm outsider status of professional contacts was negatively related to expectations for help. These findings should be informative to senior management as they consider how organization design facilitates or hinders professional contact networks and the consequent helping behaviors that arise in organizations. In particular, our findings suggest that if senior management is able to establish a global mindset that encourages executives to assist others across the organization, then this will facilitate such helping behaviors. For multinational firms competing in today's knowledge economy, this is an interesting insight. 


\section{References}

Alexander, S. Alexiev, A., Jansen, J., Van den Bosch, F., \& Volberda, H. (2010). Top management team advice seeking and exploratory innovation: The moderating role of TMT heterogeneity. Journal of Management Studies, $47,1243-1364$.

Ananthram, S, \& Nankervis, A. (2014). Outcomes and benefits of a managerial global mind-set: An exploratory study with senior executives in North America and India. Thunderbird International Business Review, 56, $193-209$.

Barkema, H., \& Vermeulen, F. (1997). What differences in cultural backgrounds of partners are detrimental for joint ventures? Journal of International Business Studies, 28, 845-865.

Baron, R., \& Kenny, D. (1986). The moderator-mediator variable distinction in social psychological research: Conceptual, strategic, and statistical considerations. Journal of Personality and Social Psychology, 51, $1173-1182$.

Beckman, C., \& Haunschild, P. (2002). Network learning: The effects of partners' heterogeneity of experience on corporate acquisitions. Administrative Science Quarterly, 47, 92-124.

Berkovitz, J., \& Feldman, M. (2011). The mechanisms of collaboration in inventive teams: Composition, social networks, and geography. Research Policy, 40, 81-93.

Blau, P. (1973). The organization of academic work. New York: Wiley.

Bradach, J., \& Eccles, R. (1989). Price, authority, and trust: From ideal types to plural forms. Annual Review of Sociology, 15, 97-118.

Brass, D., Galskiewicz, J., Greve, H., \& Tsai, W. (2004). Taking stock of networks and organizations: A multilevel perspective. Academy of Management Journal, 47, 795-817.

Burt, R. (1992). Structural Holes: The social structure of competition. Cambridge, MA: Harvard University Press.

Campbell, J., Eden, L., \& Miller, S.R. (2012). Multinationals and corporate social responsibility in host countries: Does distance matter?' Journal of International Business Studies, 43, 84-106.

Chidlow, A., Ghauri, P., Yeniyurt, S., \& Cavusgil, S.T. (2015). Establishing rigor in mail survey procedures in international business research. Journal of World Business, 50, 26-36.

Chidlow, A., Plakoyiannaki, E., \& Welsh, C. (2014). Translation in cross-language international business research: Beyond equivalence. Journal of International Business Studies, 45, 562-582

Conway, J., \& Lance, C. (2010). What reviewers should expect from authors regarding common method bias in organizational research. Journal of Business Psychology, 25, 325-334.

Coulter, K., \& Coulter, R. (2002). Determinants of trust in a service provider: The moderating role of length of relationship. Journal of Service Marketing, 16, 35-50.

Cramton, C. (2001). The mutual knowledge problem and its consequences for dispersed collaboration. Organization Science, 12, 346-371.

Dahlander, L., \& McFarland, D. (2013). Ties that last: Tie formation and persistence in research collaborations over time. Administrative Science Quarterly, 58, 69-110. 
Darr, E., Argote, L., \& Epple, D. (1995). The acquisition, transfer and depreciation of knowledge in service organizations: Productivity in franchises. Management Science, 41, 1750-1762.

Doney, P., Cannon, J., \& Mullen, M. (1998). Understanding the influence of national culture on the development of trust. Academy of Management Review, 23, 601-620.

Evans, M. (2015). Mediating effects of trust: Knowledge sharing in a large professional service firm. Proceedings of the European Conference on Intellectual Capital, 97-105.

Faulconbridge, J., \& Muzio, D. 2016. Global professional service firms and the challenge of institutional complexity: 'Field relocation' as a response strategy. Journal of Management Studies, 53, 89-124.

Farh, C., Bartol, K., Shapiro, D., \& Shin, J. (2010). Networking abroad: A process model of how expatriates form support ties to facilitate adjustment. Academy of Management Journal, 35, 434-454.

Geletkanycz, M., \& Hambrick, D. (1997). The external ties of top executives: Implications for strategic choice and performance. Administrative Science Quarterly, 42, 654-681.

Glaeser, E., Kallal, J., Scheinkman, J., \& Shleifer, A. (1992). Growth in cities. Journal of Political Economy, 100, 1126-1152.

Granovetter, M. (1973). The strength of weak ties. American Journal of Sociology, 78, 1360-1380.

Gupta, A., \& Govindarajan, V. (2002). Cultivating a global mindset. Academy of Management Executive, 16, 116126.

Haas, M., \& Cummings, J. (2015). Barriers to knowledge seeking within MNC teams: Which differences matter most? Journal of International Business Studies, 46, 36-62.

Haas, M., \& Hansen, M. 2007. Different knowledge, different benefits: Toward a productivity perspective on knowledge sharing in organizations. Strategic Management Journal, 28, 1133-1153.

Hansen, M. (1999). The search-transfer problem: The role of weak ties in sharing knowledge across organization subunits. Administrative Science Quarterly, 44, 82-111.

Hansen, M. (2002). Knowledge networks: Explaining effective knowledge sharing in multiunit companies. Organization Science, 13, 232-248.

Hansen, M., \& Løvås, B. (2004). How do multinational companies leverage technological competencies? Moving from single to interdependent explanations. Strategic Management Journal, 25, 801-822.

Harman, H. (1960). Modern factor analysis. Chicago, Ill: University of Chicago Press.

Hofstede, G. (1980). Culture's consequences: International differences in work-related values. Beverly Hills, CA: Sage Publications.

Hogg, M., \& Terry, D. (2000). Social identity and self-categorization processes in organizational contexts. Academy of Management Review, 25, 121-140.

Ibarra, H. (1992). Structural alignments, individual strategies, and managerial action: Elements toward a network theory of getting things done. In N. Nohria \& R. Eccles (Eds.), Networks and organizations: Structure form and action (pp. 165-188). Cambridge, MA: Harvard Business School Press.

Inkpen, A., \& Tsang, E. (2005). Social capital, networks, and knowledge transfer. Academy of Management Review, 30, 146-165. 
Judge, T., Bono, J., \& Locke, E. (2000). Personality and job satisfaction: The mediating role of job characteristics. Journal of Applied Psychology, 85, 237-249.

Katz, R., \& Allen, T. (1982). Investigating the not-invented-here (NIH) syndrome: a look at performance, tenure and communication patterns of $50 \mathrm{R} \& \mathrm{D}$ project groups. R\&D Management, 12, 7-19.

Kennedy, P. (1998). A guide to econometrics (4th edition). Malden, MA: Blackwell.

Kijkuit, B., \& van den Ende, J. (2010). With a little help from our colleagues: A longitudinal study of social networks for innovation. Organization Studies, 31, 451-479.

Kogut, B. (1991). Country capabilities and the permeability of borders. Strategic Management Journal, 12, 33-48.

Kogut, B., \& Singh, H. (1988). The effect of national culture on the choice of entry mode. Journal of International Business Studies, 19, 411-32.

Lazerfeld, P., \& Merton, R. (1954). Friendship as a social process: A substantive and methodological analysis. In M. Berger, T. Abel, \& C. Page (Eds.), Freedom and control in modern society (pp. 18-66). New York: Van Nostrand.

Lee, B., \& Campbell, K. (1992). Sources of personal neighbor networks: Social integration, need, or time? Social Forces, 70, 1077-1100.

Levene, H. (1960). Robust tests for equality of variances. In I. Olkin (Ed.), Contributions to probability and statistics: Essays in honor of Harold Hotelling (pp. 278-292). Stanford, CA: Stanford University Press.

Levin, D., \& Cross, R. (2004). The strength of weak ties you can trust: The mediating role of trust in effective knowledge transfer. Management Science, 50, 1477-1490.

Levin, D., Whitener, E., \& Cross, R. (2006). Perceived trustworthiness of knowledge sources: The moderating impact of relationship length. Journal of Applied Psychology, 91, 1163-1171.

Long, S. (1997). Regression models for categorical and limited dependent variables. Thousand Oaks, CA: Sage.

Marsden, P., \& Campbell, K. (1984). Measuring tie strength. Social Forces, 63, 482-501.

Mayer, R., Davis, J., \& Schoorman, F. (1995). An integrative model of organizational trust. Academy of Management Review, 20, 709-734.

McDonald, M., Khanna, P., \& Westphal, J. (2008). Getting them to think outside the circle: Corporate governance, CEO advice networks, and firm performance. Academy of Management Journal, 51, 453-475.

McDonald, M., \& Westphal, J. (2003). Getting by with the advice of their friends: CEOs' advice networks and firms' strategic responses to poor performance. Administrative Science Quarterly, 48, 1-32.

McDonald, M., \& Westphal, J. (2010). A little help here? Board control, CEO identification with the corporate elite, and strategic help provided to CEOs at other firms. Academy of Management Journal, 53, 343-370.

McPherson, M., Smith-Lovin, L., \& Cook, J. (2001). Birds of a feather: Homophily in social networks. Annual Review of Sociology, 27, 415-444.

Menon, T., \& Pfeffer, J. (2003). Valuing internal vs. external knowledge: Explaining the preference for outsiders. Management Science, 49, 497-513.

Menon, T., Thompson, L., \& Choi, H-S. (2006). Tainted knowledge vs. tempting knowledge: People avoid knowledge from internal rivals and seek knowledge from external rivals. Management Science, 52, 1129-1144. 
Moran, P. (2005). Structural vs. relational embeddedness: Social capital and managerial performance. Strategic Management Journal, 26, 1129-1151.

Mors, M. (2010). Innovation in a global consulting firm: When the problem is too much diversity. Strategic Management Journal, 31, 841-872.

Mors, M., Rogan, M., \& Lynch, S. (2018). Boundary spanning and knowledge exploration in a professional services firm. Journal of Professions and Organization, forthcoming.

Murtha, T., Lenway, S., \& Bagozzi, R. (1998). Global mind-sets and cognitive shifts in a complex multinational corporation. Strategic Management Journal, 19, 97-114.

Nebus, J. (2006). Building collegial information networks: A theory of advice network generation. Academy of Management Review, 31, 615-637.

Nonaka, I. (1994). A dynamic theory of organizational knowledge creation. Organization Science, 5, 14-37.

Nonaka, I., \& Konno, N. (1998). The concept of "Ba": Building a foundation for knowledge creation, California Management Review, 40, 40-54.

Perry-Smith, J. (2006). Social yet creative: The role of social relationships in facilitating individual creativity. Academy of Management Journal, 49, 85-101.

Powell, W., \& Smith-Doerr, L. (1994). Networks and economic life. In N. Smelser \& R. Swedberg (Eds.), The handbook of economic sociology (pp. 368-402). Princeton, NJ: Princeton University Press.

Rodan, S., \& Galunic, D. (2004). More than network structure: How knowledge heterogeneity influences managerial performance and innovativeness. Strategic Management Journal, 25, 541-556.

Rogan, M. (2014). Too close for comfort? The effect of embeddedness and competitive overlap on client relationship retention following an acquisition. Organization Science, 25, 185-203.

Sitkin, S., \& Roth, N. (1993). Explaining the limited effectiveness of legalistic "remedies" for trust/distrust. Organization Science, 4, 367-381.

Snijders, T., Spreen, M., \& Zwagstraa, R. (1995). The use of multilevel modeling for analyzing personal networks: Networks of cocaine users in an urban area. Journal of Quantitative Anthropology, 5, 85-105.

Squires, A. 2009. Methodological challenges in cross-language qualitative research: A research review. International Journal of Nursing Studies, 46, 277-287.

Story, J., \& Barbuto Jr., J. (2011). Global mindset: A construct clarification and framework. Journal of Leadership \& Organizational Studies, 18, 377-384.

Sykes, T., Venkatesh, V., \& Johnson, J. (2014). Enterprise system implementation and employee job performance: Understanding the role of advice networks. MIS Quarterly, 38, 51-A4.

Tallman, S., \& Phene, A. (2007). Leveraging knowledge across geographic boundaries. Organization Science, 18, 252 260 .

Tsui, A., \& O'Reilly, III C. (1989). Beyond simple demographic effects: The importance of relational demography in superior-subordinate dyads. Academy of Management Journal, 32, 402-423.

Vanneste, V., Puranam, P., \& Kretschmer, T. (2014). Trust over time in exchange relationships: Meta-analysis and 
theory. Strategic Management Journal, 35, 1891-1902.

Wicks, A., Berman, S., \& Jones, T. (1999). The structure of optimal trust: Moral and strategic implications. Academy of Management Review, 24, 99-116.

Welch, C., \& Piekkari, R. (2006). Crossing language barriers: Qualitative interviewing in international business. Management International Review, 46, 417-437.

Williams, M. (2001). In whom we trust: Social group membership as an affective context for trust development. Academy of Management Review, 26, 377-396.

Williams, M. (2007). Building genuine trust through interpersonal emotion management: A threat regulation model of trust and collaboration across boundaries. Academy of Management Review, 2, 595-621.

Wu, W. (2008). Dimensions of social capital and firm competitiveness improvement: The mediating role of information sharing. Journal of Management Studies, 45, 122-146.

Zaheer, S. (1995). Overcoming the liability of foreignness. Academy of Management Journal, 38, 341-363.

Zand, D. (1972). Trust and managerial problem solving. Administrative Science Quarterly, 17, 229-239.

Zipf, G. (1949). Human behavior and the principle of least effort. Menlo Park, CA: Addison-Wesley.

Zou, X., \& Ingram, P. (2013). Bonds and boundaries: Network structure, organizational boundaries, and job performance. Organizational Behavior \& Human Decision Processes, 120, 98-109. 
Table 1 Summary statistics

\begin{tabular}{|c|c|c|c|c|c|c|c|c|c|c|c|c|c|c|c|}
\hline Variable & Mean & S.D. & Min & Max & 1 & 2 & 3 & 4 & 5 & 6 & 7 & 8 & 9 & 10 & 11 \\
\hline $\begin{array}{l}\text { 1. Expectations for } \\
\text { help }\end{array}$ & 3.66 & 1.15 & 1 & 5 & & & & & & & & & & & \\
\hline 2. Junior position & 0.17 & 0.37 & 0 & 1 & .04 & & & & & & & & & & \\
\hline 3. Senior position & 0.51 & 0.50 & 0 & 1 & .01 & $-.46^{*}$ & & & & & & & & & \\
\hline 4. Expatriate & 0.09 & 0.28 & 0 & 1 & $.08^{*}$ & -.02 & -.00 & & & & & & & & \\
\hline 5. Relational strength & 3.70 & 1.03 & 1 & 5 & $.60^{*}$ & $.07^{*}$ & $-.05^{*}$ & .01 & & & & & & & \\
\hline 6. Relational duration ${ }^{\mathrm{b}}$ & 5.46 & 4.94 & 0.1 & 39 & $.25^{*}$ & $-.18^{*}$ & $.26^{*}$ & $-.08^{*}$ & $.31^{*}$ & & & & & & \\
\hline $\begin{array}{l}\text { 7. Knowledge sharing } \\
\text { help }\end{array}$ & 0.25 & 0.43 & 0 & 1 & $.17^{*}$ & -.03 & $.05^{*}$ & -.01 & $.16^{*}$ & $.07^{*}$ & & & & & \\
\hline $\begin{array}{l}\text { 8. Knowledge } \\
\text { development help }\end{array}$ & 0.20 & 0.40 & 0 & 1 & $.20^{*}$ & -.03 & $.07^{*}$ & -.04 & $.18^{*}$ & $.11^{*}$ & $.36^{*}$ & & & & \\
\hline 9. Sponsorship help & 0.22 & 0.42 & 0 & 1 & $.06^{*}$ & $-.16^{*}$ & $.33^{*}$ & .03 & $.05^{*}$ & $.11^{*}$ & -.01 & $.08^{*}$ & & & \\
\hline 10. Outsider & 0.29 & 0.45 & 0 & 1 & $-.30^{*}$ & $.07^{*}$ & $-.28^{*}$ & -.02 & $-.18^{*}$ & $-.20^{*}$ & $-.19^{*}$ & $-.20^{*}$ & $-.16^{*}$ & & \\
\hline 11. Nonlocal & 0.14 & 0.35 & 0 & 1 & -.04 & $-.08^{*}$ & $.16^{*}$ & $.12^{*}$ & $-.09^{*}$ & $-.15^{*}$ & .02 & .01 & $.06^{*}$ & $-.09^{*}$ & \\
\hline 12. Trust & 3.62 & 1.13 & 1 & 5 & $.73^{*}$ & $.05^{*}$ & -.02 & .04 & $.55^{*}$ & $.23^{*}$ & $.13^{*}$ & $.18^{*}$ & .02 & $-.27^{*}$ & $-.07^{*}$ \\
\hline
\end{tabular}

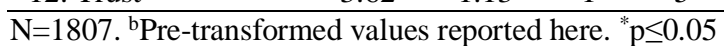


Table 2 Multilevel model results of expectations for help ${ }^{a}$

\begin{tabular}{|c|c|c|c|c|}
\hline Variable & Model 1 & Model 2 & Model 3 & Model 4 \\
\hline \multirow[t]{2}{*}{ Constant } & $0.19^{*}$ & $0.37^{* * *}$ & $1.55^{* * *}$ & $1.55^{* * *}$ \\
\hline & $(0.09)$ & $(0.10)$ & $(0.11)$ & $(0.11)$ \\
\hline \multirow[t]{2}{*}{ Junior position } & $0.12^{*}$ & $0.11^{*}$ & $0.16^{* *}$ & $0.15^{*}$ \\
\hline & $(0.05)$ & $(0.05)$ & $(0.06)$ & $(0.06)$ \\
\hline \multirow[t]{2}{*}{ Senior position } & 0.05 & 0.01 & -0.03 & -0.04 \\
\hline & $(0.04)$ & $(0.04)$ & $(0.05)$ & $(0.05)$ \\
\hline \multirow[t]{2}{*}{ Expatriate } & 0.21 & 0.20 & $0.37^{*}$ & $0.37^{*}$ \\
\hline & $(0.14)$ & $(0.14)$ & $(0.15)$ & $(0.16)$ \\
\hline \multirow[t]{2}{*}{ Relational strength } & $0.27^{* * *}$ & $0.26^{* * *}$ & $0.58^{* * *}$ & $0.59^{* * *}$ \\
\hline & $(0.02)$ & $(0.02)$ & $(0.02)$ & $(0.02)$ \\
\hline \multirow[t]{2}{*}{ Relational duration ${ }^{\mathrm{b}}$} & $0.05^{* *}$ & 0.04 & 0.03 & 0.01 \\
\hline & $(0.02)$ & $(0.00)$ & $(0.03)$ & $(0.01)$ \\
\hline \multirow[t]{2}{*}{ Trust } & $0.63^{* * *}$ & $0.61^{* * *}$ & -- & -- \\
\hline & $(0.02)$ & $(0.02)$ & & \\
\hline \multirow[t]{2}{*}{ Knowledge sharing help } & $0.11^{* *}$ & $0.09^{*}$ & $0.08^{+}$ & $0.09^{+}$ \\
\hline & $(0.04)$ & $(0.04)$ & $(0.05)$ & $(0.05)$ \\
\hline \multirow{2}{*}{$\begin{array}{l}\text { Knowledge } \\
\text { creation/development help }\end{array}$} & $0.08^{+}$ & 0.06 & $0.15^{* *}$ & $0.14^{* *}$ \\
\hline & $(0.04)$ & $(0.04)$ & $(0.05)$ & $(0.05)$ \\
\hline \multirow[t]{2}{*}{ Sponsorship help } & $0.08^{*}$ & $0.07^{+}$ & 0.06 & 0.06 \\
\hline & $(0.04)$ & $(0.04)$ & $(0.05)$ & $(0.05)$ \\
\hline \multirow[t]{2}{*}{ Outsider } & & $-0.19^{* * * *}$ & $-0.67^{* * *}$ & $-0.40^{* * * *}$ \\
\hline & & $(0.04)$ & $(0.07)$ & $(0.05)$ \\
\hline \multirow[t]{2}{*}{ Nonlocal } & & -0.03 & 0.02 & 0.02 \\
\hline & & $(0.05)$ & $(0.09)$ & $(0.07)$ \\
\hline \multirow{2}{*}{$\begin{array}{l}\text { Outsider * Relational } \\
\text { duration }^{\mathrm{b}}\end{array}$} & & -- & $0.23^{* * *}$ & $0.03^{* * *}$ \\
\hline & & & $(0.05)$ & $(0.01)$ \\
\hline \multirow{2}{*}{$\begin{array}{l}\text { Nonlocal * Relational } \\
\text { duration }^{\mathrm{b}}\end{array}$} & & -- & -0.00 & 0.01 \\
\hline & & & $(0.07)$ & $(0.02)$ \\
\hline \multirow[t]{2}{*}{ Outsider * Nonlocal } & & -- & -- & -0.04 \\
\hline & & & & $(0.14)$ \\
\hline $\mathrm{N}$ & 1807 & 1807 & 1807 & 1815 \\
\hline Wald $\mathrm{Chi}^{2}$ & $3161.91^{* * *}$ & $3226.50^{* * *}$ & $1451.88^{* * *}$ & $1447.96^{* * *}$ \\
\hline Loglikelihood & -1813.5 & -1801.81 & -2193.22 & -2215.92 \\
\hline$\Delta$ Loglikelihood & & $23.33^{* * *}$ & $21.95^{* \mathrm{c}}$ & 0.01 \\
\hline
\end{tabular}

${ }^{a}$ Analysis at the dyadic level. The dependent variable is a focal partner's expectation of a given contact's willingness to help. Country location dummies included, but not reported. Standard errors clustered on the focal partner (102 partners). ${ }^{+} \mathrm{p} \leq 0.10 ;{ }^{*} \mathrm{p} \leq 0.05 ;{ }^{* *} \mathrm{p} \leq 0.01 ;{ }^{* * *} \mathrm{p} \leq 0.001 .{ }^{\mathrm{b}}$ Logtransformed variable. ${ }^{\mathrm{c}}$ The change in loglikelihood is based on models 2 and 3 excluding trust. 
Table 3 Multilevel model results of expectations for help - Assessing mediation of trust ${ }^{\mathrm{a}}$ Mediation on nonlocal

Mediation on outsider

\begin{tabular}{|c|c|c|c|c|c|c|}
\hline & DV=Help & DV=Trust & DV=Help & DV=Help & DV=Trust & DV=Help \\
\hline Variable & Model 1 & Model 2 & Model 3 & Model 4 & Model 5 & Model 6 \\
\hline \multirow[t]{2}{*}{ Constant } & $1.45^{* * *}$ & $1.81^{* * *}$ & $0.35^{* * *}$ & $1.55^{* * *}$ & $1.87^{* * *}$ & $0.42^{* * * *}$ \\
\hline & $(0.11)$ & $(0.12)$ & $(0.10)$ & $(0.11)$ & $(0.12)$ & $(0.10)$ \\
\hline \multirow[t]{2}{*}{ Junior position } & $0.16^{* *}$ & $0.10^{+}$ & $0.11^{*}$ & $0.16^{*}$ & $0.09^{+}$ & $0.10^{*}$ \\
\hline & $(0.06)$ & $(0.06)$ & $(0.05)$ & $(0.06)$ & $(0.06)$ & $(0.05)$ \\
\hline \multirow[t]{2}{*}{ Senior position } & -0.03 & $-0.08^{+}$ & 0.01 & -0.03 & $-0.08^{+}$ & 0.02 \\
\hline & $(0.05)$ & $(0.05)$ & $(0.04)$ & $(0.05)$ & $(0.05)$ & $(0.04)$ \\
\hline \multirow[t]{2}{*}{ Expatriate } & $0.37^{*}$ & 0.26 & 0.21 & $0.37^{*}$ & 0.27 & 0.20 \\
\hline & $(0.16)$ & $(0.20)$ & $(0.14)$ & $(0.16)$ & $(0.20)$ & $(0.14)$ \\
\hline \multirow[t]{2}{*}{ Relational strength } & $0.59^{* * *}$ & $0.53^{* * *}$ & $0.26^{* * *}$ & $0.58^{* * * *}$ & $0.52^{* * *}$ & $0.26^{* * *}$ \\
\hline & $(0.02)$ & $(0.02)$ & $(0.02)$ & $(0.02)$ & $(0.02)$ & $(0.02)$ \\
\hline \multirow[t]{2}{*}{ Relational duration ${ }^{\mathrm{b}}$} & $0.09^{* *}$ & $0.08^{* *}$ & $0.05^{*}$ & 0.03 & 0.03 & 0.01 \\
\hline & $(0.03)$ & $(0.03)$ & $(0.04)$ & $(0.03)$ & $(0.03)$ & $(0.02)$ \\
\hline \multirow{2}{*}{$\begin{array}{l}\text { Knowledge sharing } \\
\text { help }\end{array}$} & 0.07 & -0.03 & $0.09^{*}$ & $0.08^{+}$ & -0.02 & $0.09^{* *}$ \\
\hline & $(0.05)$ & $(0.05)$ & $(0.04)$ & $(0.05)$ & $(0.05)$ & $(0.04)$ \\
\hline \multirow{2}{*}{$\begin{array}{l}\text { Knowledge } \\
\text { creation/dev. help }\end{array}$} & $0.15^{* *}$ & $0.16^{* *}$ & 0.06 & $0.14^{* *}$ & $0.13^{* *}$ & 0.06 \\
\hline & $(0.05)$ & $(0.05)$ & $(0.04)$ & $(0.05)$ & $(0.05)$ & $(0.04)$ \\
\hline \multirow[t]{2}{*}{ Sponsorship help } & 0.05 & -0.03 & 0.07 & 0.06 & -0.02 & $0.07^{+}$ \\
\hline & $(0.05)$ & $(0.05)$ & $(0.04)^{+}$ & $(0.05)$ & $(0.05)$ & $(0.04)$ \\
\hline \multirow[t]{2}{*}{ Outsider } & $-0.42^{* * *}$ & $-0.39^{* * * *}$ & $-0.19^{* * * *}$ & $-0.67^{* * *}$ & $-0.61^{* * * *}$ & $-0.30^{* * *}$ \\
\hline & $(0.05)$ & $(0.05)$ & $(0.04)$ & $(0.07)$ & $(0.07)$ & $(0.06)$ \\
\hline \multirow[t]{2}{*}{ Nonlocal } & 0.02 & -0.05 & 0.05 & -0.02 & 0.02 & -0.04 \\
\hline & (0.09) & $(0.09)$ & $(0.07)$ & $(0.06)$ & $(0.06)$ & $(0.05)$ \\
\hline \multirow{2}{*}{$\begin{array}{l}\text { Outsider * } \\
\text { Relational duration }{ }^{\mathrm{b}}\end{array}$} & -- & -- & -- & $0.23^{* * *}$ & $0.21^{* * *}$ & $0.10^{* *}$ \\
\hline & & & & $(0.05)$ & $(0.05)$ & $(0.04)$ \\
\hline \multirow{2}{*}{$\begin{array}{l}\text { Nonlocal * } \\
\text { Relational duration }\end{array}$} & -0.03 & 0.09 & -0.07 & -- & -- & -- \\
\hline & $(0.07)$ & $(0.06)$ & $(0.05)$ & & & \\
\hline \multirow[t]{2}{*}{ Trust } & -- & -- & $0.61^{* * *}$ & -- & -- & $0.61^{* * *}$ \\
\hline & & & $(0.02)$ & & & $(0.02)$ \\
\hline Wald $\mathrm{Chi}^{2}$ & $1398.94^{* * *}$ & $1162.82^{* * *}$ & $3201.36^{* * *}$ & $1437.48^{* * * *}$ & $1190.63^{* * *}$ & $3214.35^{* * * *}$ \\
\hline
\end{tabular}

${ }^{\mathrm{a}} \mathrm{N}=1807$. Analysis at the dyadic level. In models $1,3,4$, and 6 the dependent variable is a focal partner's expectation of a given contact's willingness to help. In models 2 and 5, the dependent variable is trust (i.e., the focal executive's assessment of the extent to which they trust a professional contact has their best interest in mind). Country location dummies included, but not reported. Standard errors clustered on the focal partner (102 partners). ${ }^{+} \mathrm{p} \leq 0.10 ;{ }^{*} \mathrm{p} \leq 0.05 ;{ }^{* *} \mathrm{p} \leq 0.01 ;{ }^{* * * *} \mathrm{p} \leq 0.001 .{ }^{\mathrm{b}} \log$ transformed variable. 
Figure 1 Expectations for help from executives' professional contacts

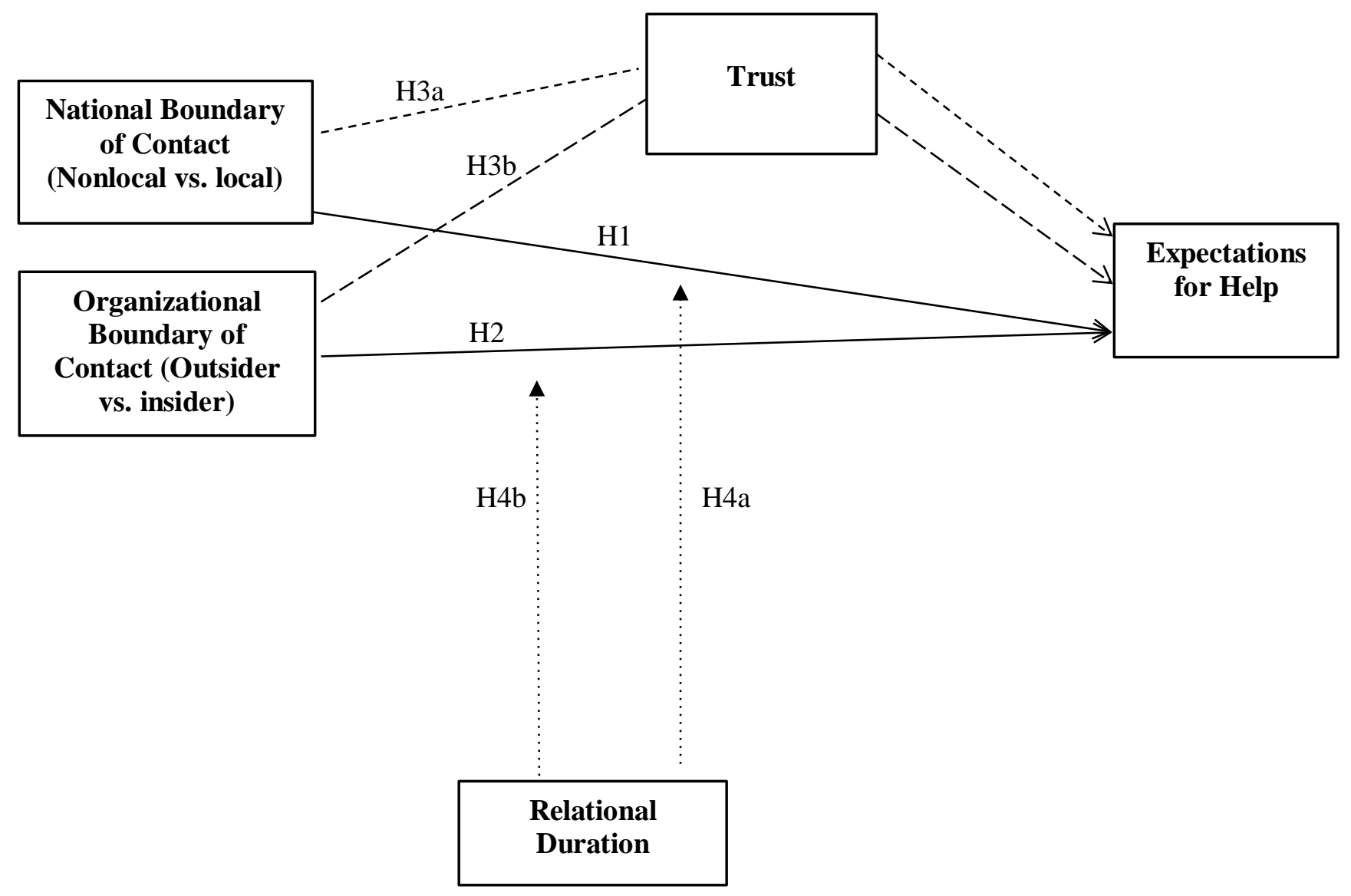


Figure 2. Predicted probability of expectations for help at different levels of relational duration for insiders and outsiders ${ }^{\mathrm{a}}$

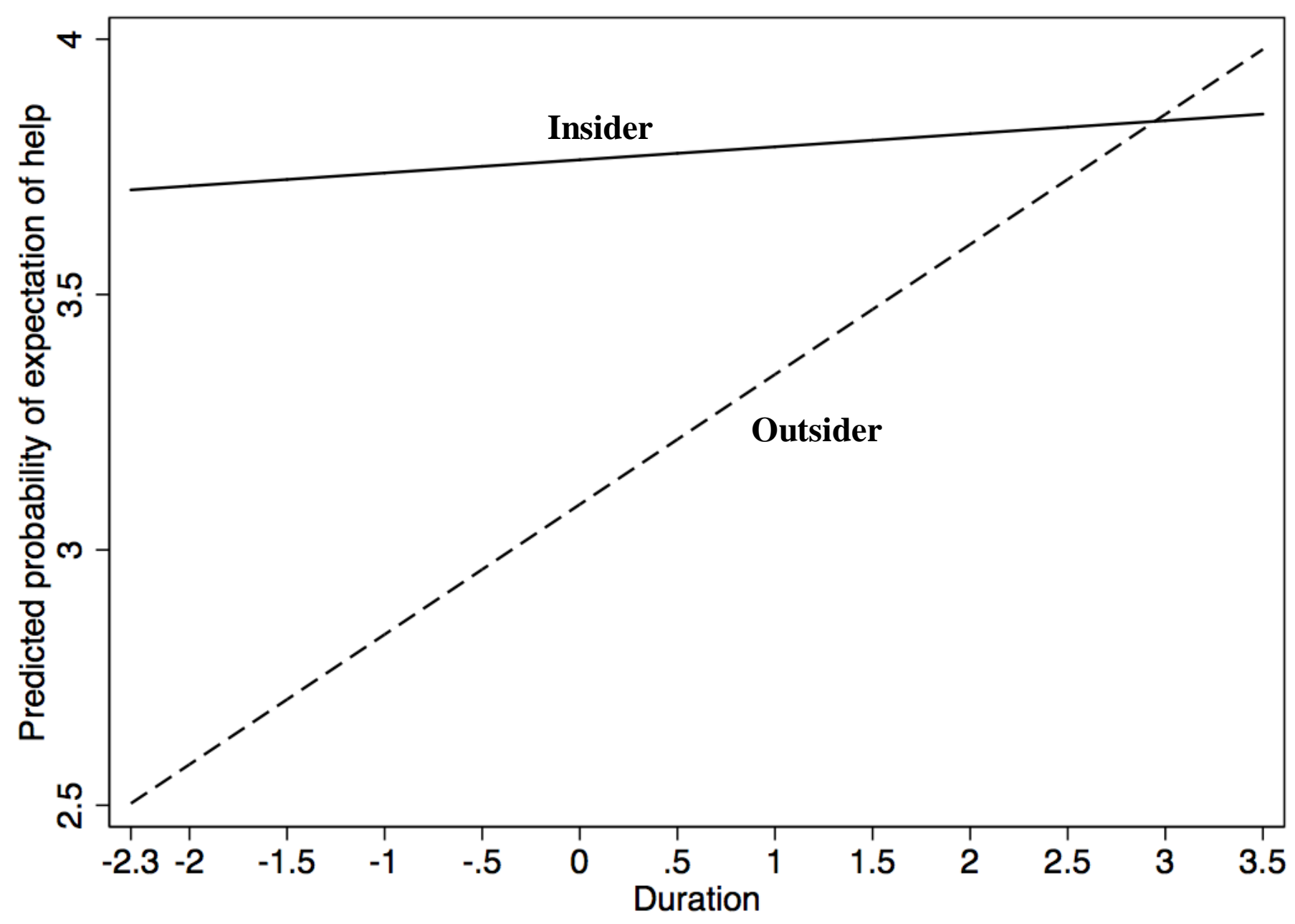

${ }^{\text {a }}$ The figure shows the marginal effects based on model 4 in Table 2. Duration is logged. 